\title{
Genetic and biological characteristics of the globally circulating H5N8 avian influenza viruses and the protective efficacy offered by the poultry vaccine currently used in China
}

\author{
Pengfei Cui ${ }^{1 \dagger}$, Xianying Zeng ${ }^{1 \dagger}$, Xuyong $\mathrm{Li}^{2 \dagger}$, Yanbing $\mathrm{Li}^{1 \dagger}$, Jianzhong $\mathrm{Shi}^{1 \dagger}$, Conghui Zhao ${ }^{1}$, \\ Zhiyuan $\mathrm{Qu}^{1}$, Yanwen Wang ${ }^{2}$, Jing Guo ${ }^{2}$, Wenli Gu ${ }^{1}$, Qi Ma ${ }^{1}$, Yuancheng Zhang ${ }^{1}$, Weipeng Lin ${ }^{1}$, \\ Minghui Li ${ }^{1}$, Jingman Tian ${ }^{1}$, Dongxue Wang ${ }^{1}$, Xin Xing ${ }^{1}$, Yanjing Liu ${ }^{1}$, Shuxin Pan ${ }^{1}$, \\ Yaping Zhang ${ }^{1}$, Hongmei Bao ${ }^{1}$, Liling Liu ${ }^{1}$, Guobin Tian ${ }^{1}$, Chengjun $\mathrm{Li}^{1,3}$, \\ Guohua Deng $^{1 *}$ \& Hualan Chen ${ }^{1,3 *}$ \\ ${ }^{1}$ State Key Laboratory of Veterinary Biotechnology, Harbin Veterinary Research Institute, Chinese Academy of Agricultural Sciences, \\ Harbin 150069, China; \\ ${ }^{2}$ College of Agronomy, Liaocheng University, Liaocheng 252000, China; \\ ${ }^{3}$ Guangdong Laboratory for Lingnan Modern Agriculture, Guangzhou 510642, China
}

Received October 16, 2021; accepted November 2, 2021; published online November 8, 2021

\begin{abstract}
The H5N8 avian influenza viruses have been widely circulating in wild birds and are responsible for the loss of over 33 million domestic poultry in Europe, Russia, Middle East, and Asia since January 2020. To monitor the invasion and spread of the H5N8 virus in China, we performed active surveillance by analyzing 317 wild bird samples and swab samples collected from 41,172 poultry all over the country. We isolated $22 \mathrm{H} 5 \mathrm{~N} 8$ viruses from wild birds and $14 \mathrm{H} 5 \mathrm{~N} 8$ viruses from waterfowls. Genetic analysis indicated that the 36 viruses formed two different genotypes: one genotype viruses were widely detected from different wild birds and domestic waterfowls; the other genotype was isolated from a whopper swan. We further revealed the origin and spatiotemporal spread of these two distinct H5N8 virus genotypes in 2020 and 2021. Animal studies indicated that the H5N8 isolates are highly pathogenic to chickens, mildly pathogenic in ducks, but have distinct pathotypes in mice. Moreover, we found that vaccinated poultry in China could be completely protected against H5N8 virus challenge. Given that the H5N8 viruses are likely to continue to spread in wild birds, vaccination of poultry is highly recommended in high-risk countries to prevent H5N8 avian influenza.
\end{abstract}

avian influenza virus, H5N8, evolution, pathogenicity, antigenicity, vaccine, protective efficacy

Citation: Cui, P., Zeng, X., Li, X., Li, Y., Shi, J., Zhao, C., Qu, Z., Wang, Y., Guo, J., Gu, W., et al. (2022). Genetic and biological characteristics of the globally circulating H5N8 avian influenza viruses and the protective efficacy offered by the poultry vaccine currently used in China. Sci China Life Sci 65 , 795-808. https://doi.org/10.1007/s11427-021-2025-y

\section{INTRODUCTION}

Influenza viruses bearing the H5 hemagglutinin (HA) have been circulating in wild birds and domestic poultry for over

†Contributed equally to this work

*Corresponding authors (Hualan Chen, email: chenhualan@caas.cn; Guohua Deng, email: dengguohua01@caas.cn) two decades since the $\mathrm{H} 5 \mathrm{~N} 1$ virus was detected in China in 1996 (Harfoot and Webby, 2017). The HA gene of H5 viruses has evolved into multiple clades, from clade 0 to clade 9, with some of these clades further divided into subclades (WHO, 2008). The H5 viruses continually reassort with other influenza viruses, forming different genotypes and subtypes (Cui et al., 2020; Lewis et al., 2021; Li et al., 2019). 
Most $\mathrm{H} 5$ viruses are confined to certain countries or regions, and only strains that infect long-distance migratory birds have spread over wide geographical areas and caused disastrous consequences (Abolnik et al., 2019; Lewis et al., 2021; Napp et al., 2018).

The first $\mathrm{H} 5$ virus that was widely spread by migratory birds was the so-called Qinghai Lake-like H5N1 virus. In May 2005, migrating bar-headed geese (Anser indicus) carrying at least three different genotypes of $\mathrm{H} 5 \mathrm{~N} 1$ viruses with a clade $2.2 \mathrm{HA}$ gene flew over the Himalayas to the egg island in Qinghai Lake in western China, a major breeding ground for migratory birds (Chen et al., 2006; Liu et al., 2005). The viruses spread to several other species on the island, including great black-headed gulls (Larus ichthyaetus), brown-headed gulls (Larus brunnicephalus), great cormorants (Phalacrocorax carbo), ruddy shelducks ( $\mathrm{Ta}$ dorna ferruginea), and whooper swans (Cygnus cygnus), and caused the death of over 6,000 wild birds in the lake from 4 May to 29 June 2005 (Chen et al., 2006). The viruses were subsequently spread by whooper swans to Mongolia and Russia in August 2005, and were then widely detected in wild birds and domestic poultry in European and African countries in 2006 (Olsen et al., 2006). These viruses were eradicated in China and many other countries in a relatively short time, but they circulated in poultry for many years and caused severe disease in poultry and humans in Egypt (ElShesheny et al., 2021).

The spread of the H5N8 viruses, which started in 2014, caused several waves of disease outbreaks in wild birds and domestic poultry across different continents. In early 2014, novel reassortant $\mathrm{H} 5 \mathrm{~N} 8$ viruses bearing the subclade 2.3.4.4 HA gene caused multiple outbreaks in migratory birds and domestic ducks in South Korea (Jeong et al., 2014). During these outbreaks, two distinct groups of H5N8 viruses, Buan2-like and Cochang1-like, were identified. The Buan2like H5N8 viruses predominated (Jeong et al., 2014), were subsequently spread to Europe, North America, and East Asia by migratory birds, and formed three distinct subgroups (Dalby and Iqbal, 2015; Lee et al., 2015). In late May 2016, Cochang1-like H5N8 viruses were detected in wild migratory birds at Ubsu-Nur Lake in Mongolia, and then rapidly spread to other European Countries. By August 2017, 1,112 outbreaks in domestic and 955 outbreaks in wild birds in 30 European countries had been reported (Napp et al., 2018). In addition, Cochang1-like H5N8 viruses were detected in many countries in Asia and Africa during the second wave of H5N8 outbreaks in 2016-2017 (Abolnik et al., 2019; Kim et al., 2017; Selim et al., 2017). Although similar H5N8 viruses were also detected in swans and grey-legged geese in China at the end of 2016 and in earlier 2017 (Cui et al., 2020), they did not infect and spread among domestic poultry in China.

In January 2020, H5N8 viruses caused outbreaks in chickens in Poland and then started a new wave of outbreaks in poultry and wild birds globally (Baek et al., 2021; Khalil et al., 2021; Lewis et al., 2021). By early June 2021, 2,782 H5N8 outbreaks were reported in more than 25 countries, and more than 33 million domestic poultry died or were destroyed (http://empres-i.fao.org/eipws3g/). To monitor the invasion and spread of the H5N8 virus in China, we performed active surveillance in wild birds and in domestic poultry from September 2020 to June 2021. We found that the H5N8 viruses were introduced to China by migratory swans and were then spread to other species of wild birds across a wide geographic area in China. However, H5N8 virus did not cause any disease outbreak in the domestic poultry in China (http://empres-i.fao.org/eipws3g/). We performed a detailed analysis to trace the origin and to reveal the genetic relationship and biologic properties of the H5N8 viruses detected in China, and we uncovered the mystery of why poultry in China have avoided the issues caused by the H5N8 virus. Our study provides important insights into the spread and evolution of H5N8 viruses, and emphasizes the importance of poultry vaccination to protect against $\mathrm{H} 5 \mathrm{~N} 8$ viruses.

\section{RESULTS}

\section{Isolation and genetic analysis of $\mathrm{H5N8}$ viruses}

From September 2020 to June 2021, we collected and analyzed 317 wild bird samples (swabs or organs of 33 birds and 284 fresh feces), and 41,172 poultry swab samples $(25,523$ chickens, 13,908 ducks, 1,552 geese, and 189 pigeons) from live poultry markets, slaughterhouses, and farms. A total of $36 \mathrm{H} 5 \mathrm{~N} 8$ avian influenza viruses were isolated from these samples: 22 viruses were isolated from dead wild birds and wild bird feces found in a variety of habitats (Table 1), and eight and six viruses were isolated from duck swabs and goose swabs, respectively, that were collected in live poultry markets and slaughterhouses (Table 1).

To investigate the genetic relationship of these $\mathrm{H} 5 \mathrm{~N} 8$ viruses, we fully sequenced the whole genomes of all 36 viruses (the sequence data have been deposited in the Global Initiative on Sharing Avian Influenza Data; the accession numbers are EPI1921367-EPI921654) and compared them with representative $\mathrm{H} 5$ viruses of different clades. We found that 35 of the 36 viruses were genetically similar with each of their eight gene segments sharing $98.4 \%-100 \%$ identity at the nucleotide level with those of the index H5N8 isolate WS/SX/4-1/2020 (Table S1 in Supporting Information). However, one virus, A/whooper swan/Shandong/SC195/ 2021 (WS/SD/SC195/2021), was distinct from the others: its M gene shares $97.7 \%$ identity with that of WS/SX/4-1/2020, and its other seven genes share less than $96 \%$ identity with those of WS/SX/4-1/2020 (Table S1 in Supporting 
Table 1 Information of H5N8 viruses isolated in this study

\begin{tabular}{|c|c|c|c|c|c|c|c|}
\hline \multicolumn{3}{|c|}{ Virus } & \multicolumn{5}{|c|}{ Sample information } \\
\hline No. & Full name & Abbreviation & Sample type & Collected date & Province & Location & Species \\
\hline 1 & $\begin{array}{c}\text { A/whooper swan/Shanxi/4-1/ } \\
2020\end{array}$ & $\mathrm{WS} / \mathrm{SX} / 4-1 / 2020$ & Tissue & $\begin{array}{l}\text { November } 10 \text {, } \\
2020\end{array}$ & Shanxi & Wetland & Whooper swan \\
\hline 2 & $\begin{array}{c}\text { A/whooper swan/Shanxi/4-2/ } \\
2020\end{array}$ & $\mathrm{WS} / \mathrm{SX} / 4-2 / 2020$ & Tissue & $\begin{array}{l}\text { November } 10 \\
2020\end{array}$ & Shanxi & Wetland & Whooper swan \\
\hline 3 & A/mute swan/Shandong/1/2021 & $\mathrm{MS} / \mathrm{SD} / 1 / 2021$ & Tissue & January 14, 2021 & Shandong & Wetland & Mute swan \\
\hline 4 & $\begin{array}{l}\text { A/green-winged teal/Guangdong/ } \\
\text { SD004/2021 }\end{array}$ & GWT/GD/SD004/2021 & Swab & January 20, 2021 & Guangdong & Park & Green-winged teal \\
\hline 5 & $\begin{array}{l}\text { A/whooper swan/Shandong/ } \\
\text { SC195/2021 }\end{array}$ & $\mathrm{WS} / \mathrm{SD} / \mathrm{SC} 195 / 2021$ & Swab & January 23, 2021 & Shandong & Wetland & Whooper swan \\
\hline 6 & $\begin{array}{l}\text { A/wild goose/Shandong/SC196/ } \\
2021\end{array}$ & WG/SD/SC196/2021 & Swab & January 23, 2021 & Shandong & Wetland & Wild goose \\
\hline 7 & $\begin{array}{l}\text { A/common coot/Shandong/ } \\
\text { SC197/2021 }\end{array}$ & $\mathrm{CC} / \mathrm{SD} / \mathrm{SC} 197 / 2021$ & Swab & January 23, 2021 & Shandong & Wetland & Common coot \\
\hline 8 & $\begin{array}{l}\text { A/whooper swan/Shandong/ } \\
\text { SC198/2021 }\end{array}$ & WS/SD/SC198/2021 & Feces & January 23, 2021 & Shandong & Wetland & Whooper swan \\
\hline 9 & $\begin{array}{l}\text { A/whooper swan/Shandong/ } \\
\text { SC199/2021 }\end{array}$ & WS/SD/SC199/2021 & Feces & January 23, 2021 & Shandong & Wetland & Whooper swan \\
\hline 10 & $\begin{array}{l}\text { A/whooper swan/Shandong/ } \\
\text { SC200/2021 }\end{array}$ & $\mathrm{WS} / \mathrm{SD} / \mathrm{SC} 200 / 2021$ & Feces & January 23, 2021 & Shandong & Wetland & Whooper swan \\
\hline 11 & A/black swan/Beijing/1/2021 & $\mathrm{BS} / \mathrm{BJ} / 1 / 2021$ & Tissue & January 25, 2021 & Beijing & Park & Black swan \\
\hline 12 & A/wild duck/Jiangsu/SD019/2021 & WD/JS/SD019/2021 & Swab & January 26, 2021 & Jiangsu & Hill & Wild duck \\
\hline 13 & A/egret/Jiangsu/SD021/2021 & ET/JS/SD021/2021 & Swab & January 26, 2021 & Jiangsu & Hill & Egret \\
\hline 14 & A/duck/Guangxi/S10099/2021 & DK/GX/S10099/2021 & Swab & February 1, 2021 & Guangxi & Poultry market & Duck \\
\hline 15 & A/duck/Guangxi/S10263/2021 & $\mathrm{DK} / \mathrm{GX} / \mathrm{S} 10263 / 2021$ & Swab & February 1, 2021 & Guangxi & Poultry market & Duck \\
\hline 16 & A/duck/Guangxi/S11043/2021 & DK/GX/S11043/2021 & Swab & February 1, 2021 & Guangxi & Poultry market & Duck \\
\hline 17 & $\begin{array}{l}\text { A/whooper swan/Shandong/ } \\
\text { SC176/2021 }\end{array}$ & $\mathrm{WS} / \mathrm{SD} / \mathrm{SC} 176 / 2021$ & Feces & February 22, 2021 & Shandong & Wetland & Whooper swan \\
\hline 18 & $\begin{array}{l}\text { A/wild duck/Shandong/SC177/ } \\
2021\end{array}$ & $\mathrm{WD} / \mathrm{SD} / \mathrm{SC} 177 / 2021$ & Feces & February 22, 2021 & Shandong & Wetland & Wild duck \\
\hline 19 & A/grebe/Shandong/SC184/2021 & $\mathrm{GB} / \mathrm{SD} / \mathrm{SC} 184 / 2021$ & Swab & February 22, 2021 & Shandong & Wetland & Grebe \\
\hline 20 & $\begin{array}{l}\text { A/whooper swan/ } \\
\text { Shandong/SC185/2021 }\end{array}$ & $\mathrm{WS} / \mathrm{SD} / \mathrm{SC} 185 / 2021$ & Feces & February 22, 2021 & Shandong & Wetland & Whooper swan \\
\hline 21 & $\begin{array}{l}\text { A/whooper swan/Shandong/ } \\
\text { SC188/2021 }\end{array}$ & $\mathrm{WS} / \mathrm{SD} / \mathrm{SC} 188 / 2021$ & Feces & February 22, 2021 & Shandong & Wetland & Whooper swan \\
\hline 22 & $\begin{array}{l}\text { A/black-backed gull/ } \\
\text { Shandong/SC189/2021 }\end{array}$ & BBGL/SD/SC189/2021 & Swab & February 22, 2021 & Shandong & Wetland & Black-backed gull \\
\hline 23 & A/duck/Guangdong/S1269/2021 & $\mathrm{DK} / \mathrm{GD} / \mathrm{S} 1269 / 2021$ & Swab & March 2, 2021 & Guangdong & Poultry market & Duck \\
\hline 24 & A/duck/Jiangxi/S10252/2021 & DK/JX/S10252/2021 & Swab & March 9, 2021 & Jiangxi & Poultry market & Duck \\
\hline 25 & A/goose/Zhejiang/S1266/2021 & $\mathrm{GS} / \mathrm{ZJ} / \mathrm{S} 1266 / 2021$ & Swab & March 9, 2021 & Zhejiang & Poultry market & Goose \\
\hline 26 & A/goose/Hunan/S11288/2021 & GS/HuN/S11288/2021 & Swab & March 19, 2021 & Hunan & Poultry market & Goose \\
\hline 27 & A/goose/Jiangsu/S1385/2021 & GS/JS/S1385/2021 & Swab & March 24, 2021 & Jiangsu & Poultry market & Goose \\
\hline 28 & A/goose/Liaoning/S1266/2021 & GS/LN/S1266/2021 & Swab & April 13, 2021 & Liaoning & Slaughterhouse & Goose \\
\hline 29 & A/goose/Henan/S1315/2021 & $\mathrm{GS} / \mathrm{HeN} / \mathrm{S} 1315 / 2021$ & Swab & April 22, 2021 & Henan & Poultry market & Goose \\
\hline 30 & A/duck/Henan/S1381/2021 & $\mathrm{DK} / \mathrm{HeN} / \mathrm{S} 1381 / 2021$ & Swab & April 22, 2021 & Henan & Poultry market & Duck \\
\hline 31 & A/duck/Hebei/S1070/2021 & $\mathrm{DK} / \mathrm{HeB} / \mathrm{S} 1070 / 2021$ & Swab & April 27, 2021 & Hebei & Slaughterhouse & Duck \\
\hline 32 & A/duck/Guangxi/S21194/2021 & DK/GX/S21194/2021 & Swab & May 10, 2021 & Guangxi & Poultry market & Duck \\
\hline 33 & A/goose/Guangxi/S20601/2021 & GS/GX/S20601/2021 & Swab & May 11, 2021 & Guangxi & Poultry market & Goose \\
\hline 34 & $\begin{array}{l}\text { A/brown-headed gull/ } \\
\text { Tibet } / 1-1 / 2021\end{array}$ & BHGL/TB/1-1/2021 & Tissue & May 16, 2021 & Tibet & Wetland & Brown-headed gull \\
\hline 35 & A/grebe/Shaanxi/SD001/2021 & GB/SN/SD001/2021 & Tissue & June 5, 2021 & Shaanxi & Wetland & Grebe \\
\hline 36 & A/grebe/Ningxia/SD001/2021 & GB/NX/SD001/2021 & Tissue & June 15, 2021 & Ningxia & Wetland & Grebe \\
\hline
\end{tabular}


Information). Phylogenetic analysis of the HA gene indicated that all of the $\mathrm{H} 5 \mathrm{~N} 8$ viruses in this study belong to the clade 2.3.4.4b, although $\mathrm{WS} / \mathrm{SD} / \mathrm{SC} 195 / 2021$ is located on a different branch of the tree (Figure 1A; Figure S1A in Supporting Information). Similarly, the PB2, PB1, PA, NP, NA, M, and NS genes of WS/SD/SC195/2021 are located on a different branch of their respective trees (Figure S1B-H in Supporting Information). Based on their genomic similarity, the $36 \mathrm{H} 5 \mathrm{~N} 8$ viruses in this study were divided into two genotypes: 35 viruses belonging to genotype one (G1), which were detected in 11 different kinds of wild birds and domestic ducks and geese in 15 different provinces; and one virus (WS/SD/SC195/2021), which was detected in a whooper swan in Shandong province, belonging to genotype two (G2) (Figure 1B and C).

\section{Origin and spatiotemporal spread of H5N8 virus since 2020}

The H5N8 viruses have been widely detected in different

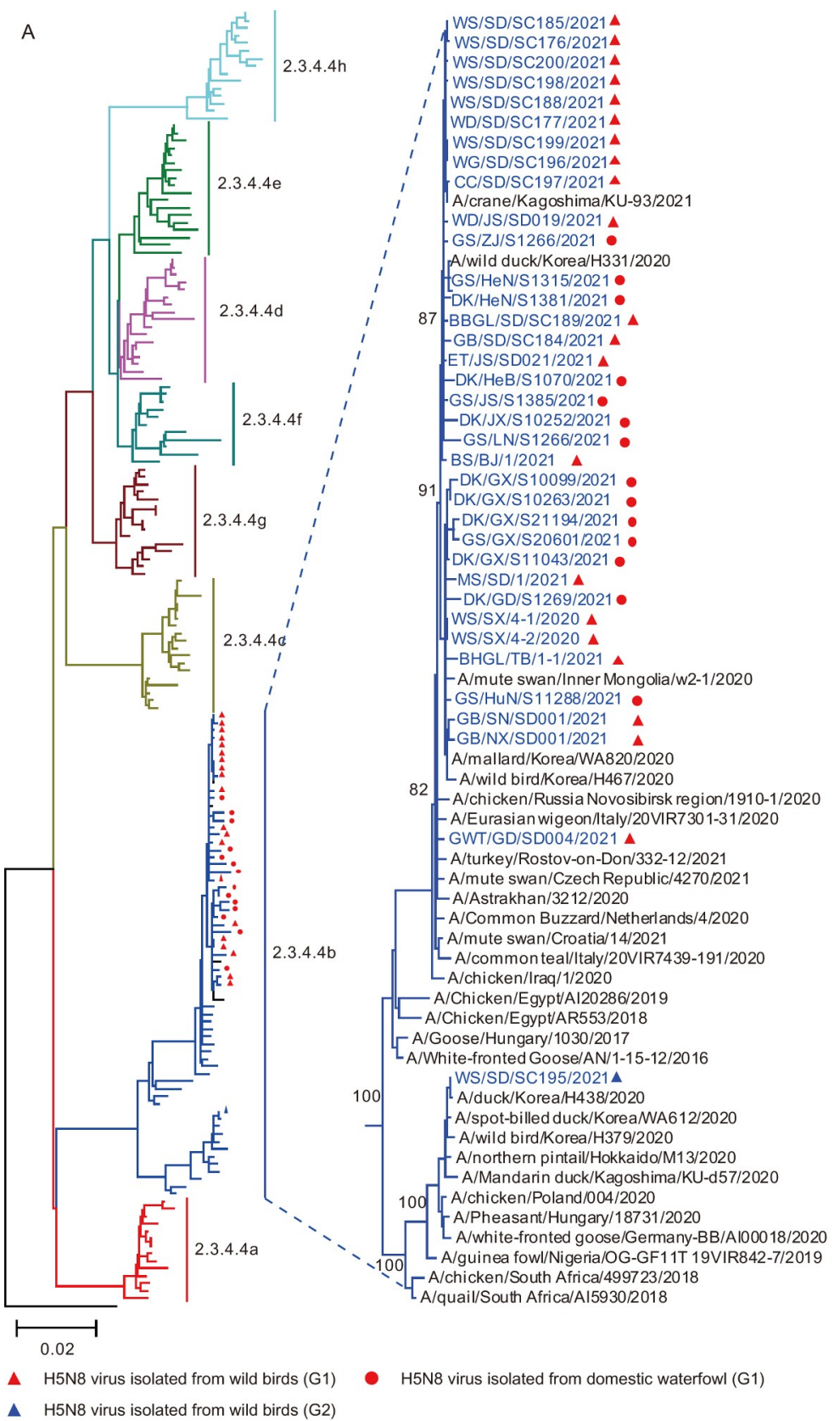

B

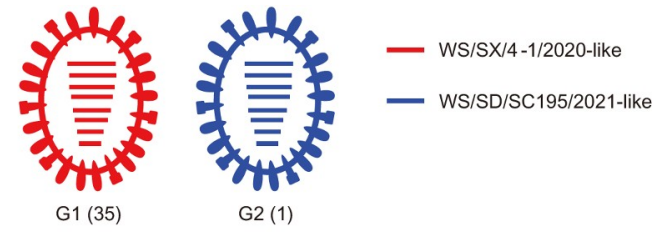



Wild birds:
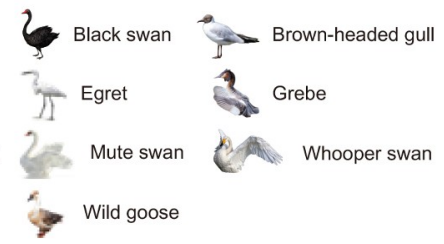

Domestic waterfowl:

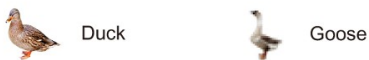



Figure 1 Phylogenetic analyses, genotypes, and distribution of H5N8 viruses in China. A, The big tree shows the phylogenetic relationship of the HA genes of $177 \mathrm{H} 5$ viruses belonged to clade 2.3.4.4, including $36 \mathrm{H} 5 \mathrm{~N} 8$ viruses sequenced in this study; the viral names of 65 viruses belonged to clade $2.3 .4 .4 \mathrm{~b}$ are shown in the small tree, and the viruses sequenced in this study are shown in blue. The phylogenetic tree of HA (A) was rooted to A/duck/Anhui/1/2006 (H5N1). Phylogenetic trees of the eight gene segments with complete information are shown in Figure S1 in Supporting Information. B, Genotypes of the H5N8 viruses. Numbers of strains of each genotype are indicated in parentheses. C, Geographic, host species, and genotype distribution of the H5N8 viruses. 
avian species in many countries since the beginning of 2020 . To better understand their origin, as well as the timeline of invasion and spread of H5N8 viruses in China, we constructed a Bayesian time-resolved phylogenetic tree with the $\mathrm{HA}$ of the $36 \mathrm{H} 5 \mathrm{~N} 8$ viruses in this study, four $\mathrm{H} 5 \mathrm{~N} 8$ viruses isolated in China by others (Li et al., 2021; Xiong et al., 2021), and the HA of 202 representative viruses that were detected in 2020 and 2021 in other countries (Figure 2). We found that the HA of these H5N8 viruses formed two branches (branch I and branch II) that probably separated in early 2018. The viruses in branch I circulated in domestic poultry and wild birds in Poland, Hungary, Germany, and Czech Republic in the spring and summer of 2020, and were then detected in domestic poultry and wild birds in Japan and Korea in the winter of 2020. In January 2021, a virus (WS/ $\mathrm{SD} / \mathrm{SC} 195 / 2021)$ of branch I was detected in a whopper swan in Shandong Province (Figure 2). The branch II viruses were firstly detected in chickens in Iraq in May 2020, then caused multiple disease outbreaks in domestic poultry in July and August 2020 in Russia, and were responsible for the subsequently widespread disease outbreaks in wild birds and domestic poultry in Russia and many countries in Middle East, Europe, Africa, and Asia. The branch II viruses began to be detected in swans and other wild birds in China from October 2020, and were also detected in ducks and geese in 2021. Thirty-nine viruses isolated in China are in three different forks of branch II (Figure 2). Of note, H5N8 viruses bearing the branch II HA gene were also detected in humans in Russia and in seals and a fox in the United Kingdom (Figure 2; Figure S2 in Supporting Information) (Pyankova et al., 2021; Rodriguez-Morales et al., 2021; Shin et al., 2019). Since the sequence of the fox virus was not available, we did not list fox as a host for H5N8 virus in Figure 2. These analyses indicate that the $\mathrm{H} 5 \mathrm{~N} 8$ viruses have been detected in at least 46 different species of wild birds in 25 countries since January 2020, and migratory swans carried and introduced the H5N8 viruses bearing HA from two different branches to China in October 2020 and January 2021. The branch II viruses were subsequently spread to other wild birds and domestic waterfowls in China.

\section{Molecular characteristics of the H5N8 viruses isolated in China}

All of the $36 \mathrm{H} 5 \mathrm{~N} 8$ viruses have the same amino acid motif of -PLREKRRKR/G- at their HA cleavage site, which meets the criterion for highly pathogenetic avian influenza viruses (Neumann and Kawaoka, 2006). All 36 viruses also have the amino acids $137 \mathrm{~A}, 158 \mathrm{~N}$, and $160 \mathrm{~A}$ and 33 viruses have $192 \mathrm{I}$ (H3 numbering) in their HA (Table S2 in Supporting Information); these amino acids have been reported to increase the affinity of $\mathrm{H} 5$ influenza virus for human-type receptors (Gao et al., 2009; Wang et al., 2010; Yang et al., 2007).
Several amino acid changes linked to increased replication and virulence in mammals were detected in these $\mathrm{H} 5 \mathrm{~N} 8$ viruses (Table S2 in Supporting Information). All 36 viruses have 389R and 598T in PB2, 286A and 437T in NP, 30D and $215 \mathrm{~A}$ in $\mathrm{M} 1$, and $42 \mathrm{~S}$ and $106 \mathrm{M}$ in NS1; 33 of the 36 viruses have 292I in PB2 (Table S2 in Supporting Information). These amino acids have been reported to increase the replication, virulence, or transmission of different influenza viruses in mammalian animals (Ayllon et al., 2014; Fan et al., 2009; Hu et al., 2017; Jiao et al., 2008; Kong et al., 2019; Ma et al., 2020). Moreover, one virus (GWT/GD/SD004/2021) has $27 \mathrm{~A}$ and one virus (GB/NX/SD001/2021) has 30S in M2 (Table S2 in Supporting Information), suggesting that these two viruses may have increased resistance to amantadine (Hay et al., 1986).

\section{Replication and virulence of $\mathrm{H5N8}$ viruses in mice}

In December 2020, seven poultry workers tested positive for $\mathrm{H} 5 \mathrm{~N} 8$ virus during an outbreak at a large poultry farm in southern Russia (Pyankova et al., 2021). To understand the virulence in mammals of the H5N8 viruses isolated in China, we tested four representative strains in mice. We found that two viruses, WS/SX/4-1/2021 and BS/BJ/1/2021, replicated systemically in mice, and were detected in all five tested organs of mice (Figure $3 \mathrm{~A}$ ). The $50 \%$ mouse lethal doses $\left(\mathrm{MLD}_{50}\right)$ of $\mathrm{WS} / \mathrm{SX} / 4-1 / 2021$ and $\mathrm{BS} / \mathrm{BJ} / 1 / 2021$ were 3.3 $\log _{10} 50 \%$ egg infectious doses $\left(\mathrm{EID}_{50}\right)$ and $2.3 \log _{10} \mathrm{EID}_{50}$, respectively (Figure 3B). The GS/HuN/S11288/2021 was detected in the nasal turbinate, lungs, and spleen of mice, but was not detected in the kidneys or brain of any mice (Figure $3 \mathrm{~A}$ ); only one and three of the five mice that were respectively inoculated with $10^{5} \mathrm{EID}_{50}$ and $10^{6} \mathrm{EID}_{50}$ of virus died during the observation period, yielding an $\mathrm{MLD}_{50}$ of 5.7 $\log _{10} \mathrm{EID}_{50}$ (Figure 3B). However, WS/SD/SC195/2021 replicated poorly and was only detected in the nasal turbinate and lungs of mice (Figure 3A); it did not kill any mice, yielding an $\mathrm{MLD}_{50}$ greater than $6.5 \log _{10} \mathrm{EID}_{50}$ (Figure $3 \mathrm{~B}$ ). These results indicate that $\mathrm{H} 5 \mathrm{~N} 8$ viruses circulating in nature have different pathotypes in mice.

\section{Replication and virulence of $\mathrm{H5N8}$ viruses in chickens and ducks}

The motif of the HA cleavage site is an important indicator of the virulence of $\mathrm{H} 5$ and $\mathrm{H} 7$ viruses in poultry (Neumann and Kawaoka, 2006); however, not all $\mathrm{H} 5$ and $\mathrm{H} 7$ viruses bearing the multiple-basic amino acid motif in HA are lethal to chickens or ducks (Li et al., 2006; Shi et al., 2018; Zhu et al., 2008). To investigate the replication and virulence of the $\mathrm{H} 5 \mathrm{~N} 8$ viruses in poultry, we tested the above-mentioned four viruses in chickens and ducks. As shown in Figure 4, all four viruses replicated efficiently in chickens, and were detected 


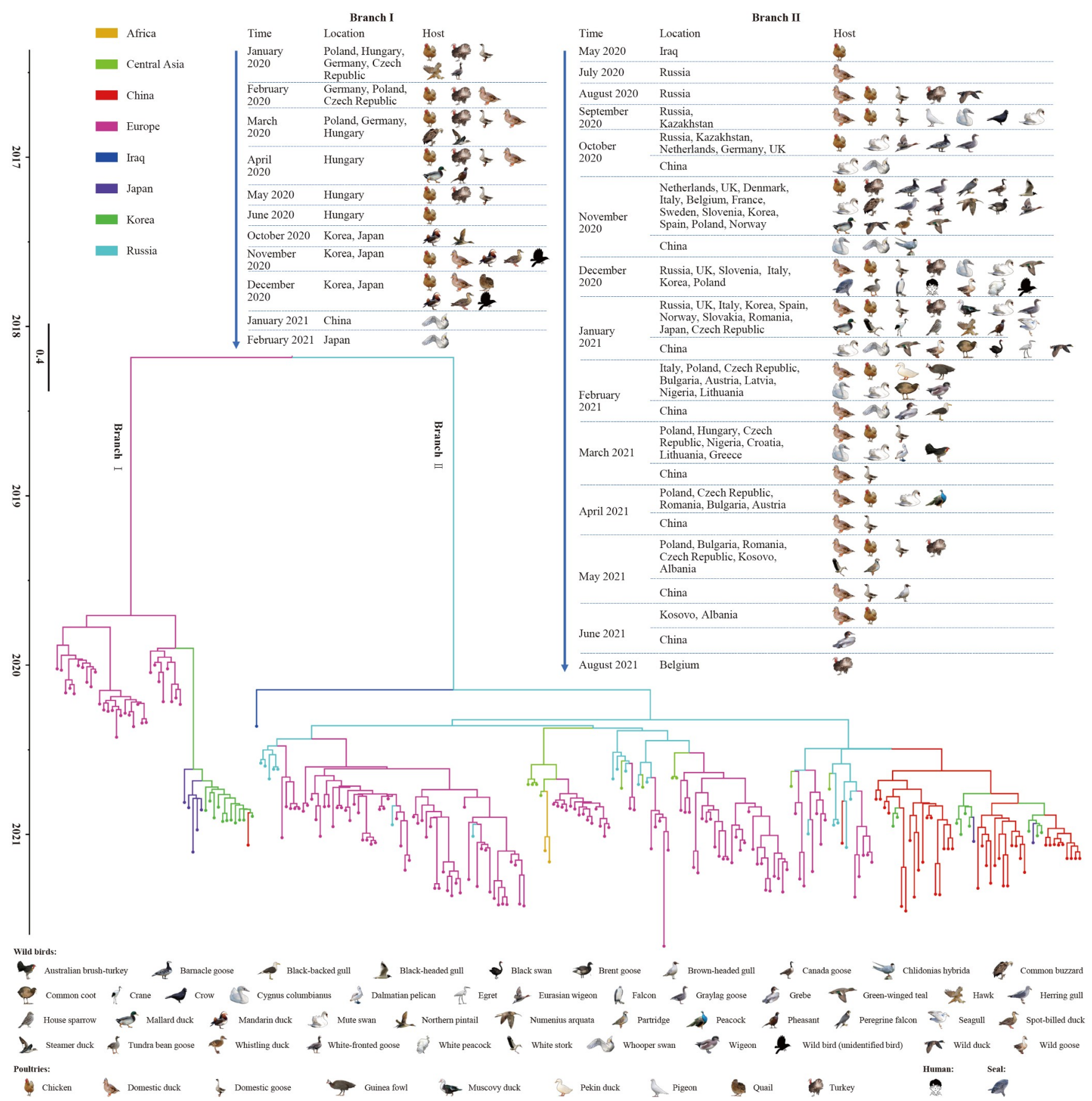

Figure 2 Spatiotemporal movement of H5N8 viruses since 2020. The Bayesian time-resolved phylogenetic tree was generated with the HA of the $40 \mathrm{H} 5 \mathrm{~N} 8$ viruses detected in China and $202 \mathrm{H} 5 \mathrm{~N} 8$ representative viruses detected in other countries since 2020. The time to the most recent common ancestor and the dates of divergence are labeled at the left of the tree, which was estimated by using the Bayesian Markov chain Monte Carlo method in the BEAST v1.10.4 software package. Information about the time (month), countries, and hosts where the viruses were detected is also shown. The tree with the full names of the viruses is provided in Figure S2 in Supporting Information.

in both the oropharyngeal and cloacal swabs of chickens (Figure 4A), and in the organs of chickens that were euthanized on Day 3 post-inoculation (p.i.), with titers ranging from $10^{4.6} \mathrm{EID}_{50} \mathrm{~mL}^{-1}$ to $10^{6.4} \mathrm{EID}_{50} \mathrm{~mL}^{-1}$ (Figure $4 \mathrm{~B}$ ). The other five chickens in each group died within 4 days of virus inoculation (Figure 4E). The replication of the four viruses in ducks varied among strains: WS/SX/4-1/2020, BS/BJ/1/2021, and WS/SD/SC195/2021 replicated well in ducks and were detected in oropharyngeal and cloacal swabs of all tested ducks (Figure 4C), and in most of the tested organs of ducks (Figure 4D); GS/HuN/S11288/2021 replicated relatively poorly in ducks, was not detected in the liver or brain of any duck inoculated, but was detected in swabs and lungs from two ducks and in other organs of one duck (Figure 4D). Four 
A



BS/BJ/1/2021



WS/SD/SC195/2021

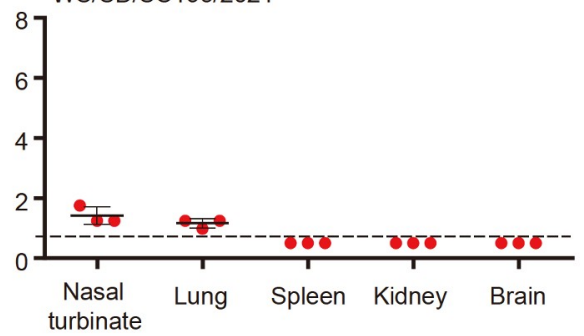

B
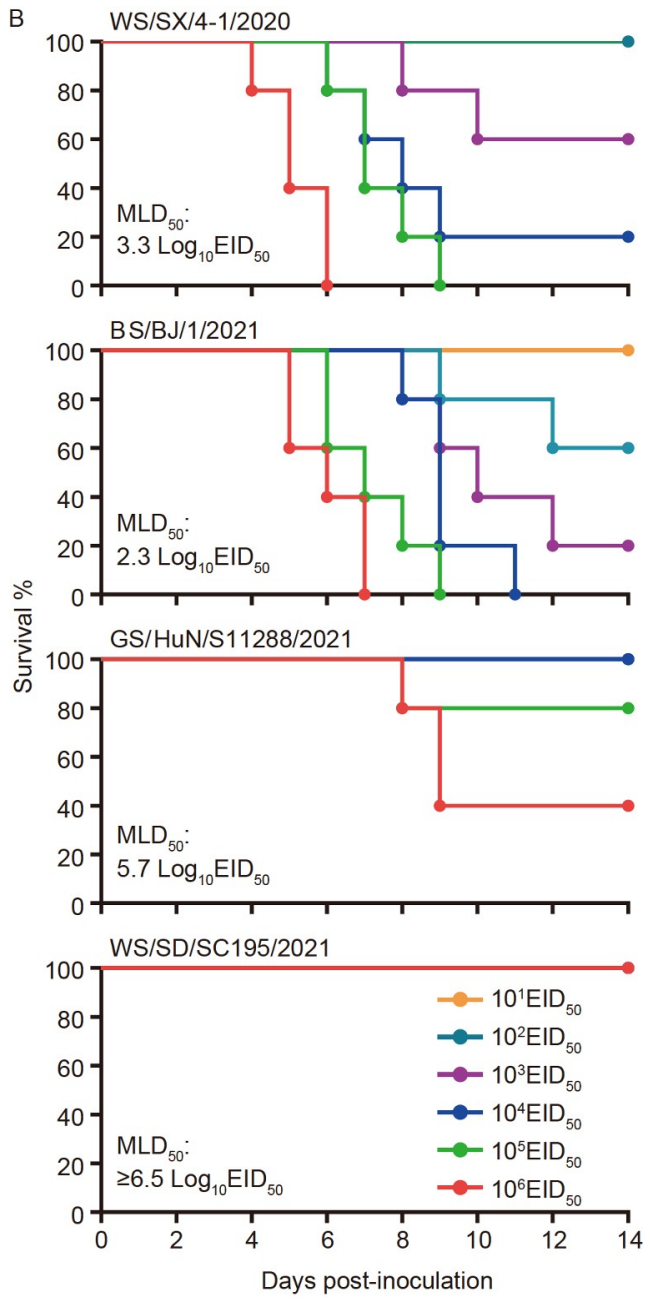

Figure 3 Replication and virulence of H5N8 viruses in mice. A, Viral titers in organs of mice after inoculation with $10^{6}$ EID $_{50}$ of different viruses. Three mice from each group were euthanized on Day 3 p.i., and virus titers in the organs were determined in eggs. The error bars represent standard deviations, and the dashed lines indicate the lower limit of virus detection. B, Mouse-lethal doses of the indicated viruses.

ducks in each of the WS/SX/4-1/2020- and BS/BJ/1/2021inoculated groups and all five ducks in the GS/HuN/S11288/ 2021- and WS/SD/SC195/2021-inoculated groups survived their infection (Figure 4F); all surviving ducks seroconverted at the end of the observation period (Figure 4G). These results indicate that the $\mathrm{H} 5 \mathrm{~N} 8$ viruses are highly pathogenic in chickens, but cause relatively mild infection in ducks.

\section{Cross-reactivity of antisera induced by current $\mathrm{H5}$ vac- cine strains used in China to $\mathrm{H5N8}$ viruses}

Vaccines have been used in poultry in China to control the H5 avian influenza virus since 2004, and vaccine seed viruses have been updated regularly in China to ensure an antigenic match between the vaccine strains and the prevalent strains (Li et al., 2014; Zeng et al., 2020). Because of the emergence of highly pathogenic H7N9 viruses in 2017, a bivalent $\mathrm{H} 5 / \mathrm{H} 7$ inactivated vaccine was developed and used to control both the $\mathrm{H} 5$ and $\mathrm{H} 7$ viruses in poultry in China
(Shi et al., 2018; Zeng et al., 2018). The current vaccine is an $\mathrm{H} 5 / \mathrm{H} 7$ trivalent inactivated vaccine containing the Re-11, Re-12, and H7-Re3 vaccine seed viruses, which were generated by reverse genetics and derived their HA genes from A/duck/Guizhou/S4184/2017(H5N6) (DK/GZ/S4184/17) (a clade 2.3.4.4h virus), A/chicken/Liaoning/SD007/2017 (H5N1) (CK/LN/SD007/17) (a clade 2.3.2.1d virus) (Zeng et al., 2020), and A/chicken/Inner Mongolia/SD010/2019 (H7N9) (CK/IM/SD010/2019), respectively (MARA, 2020). To evaluate the antigenic difference between the currently used $\mathrm{H} 5$ vaccine strains and the emerged $\mathrm{H} 5 \mathrm{~N} 8$ viruses, we performed hemagglutinin inhibition (HI) assays by using antisera generated in specific-pathogen-free (SPF) chickens against the Re-11 and Re-12 vaccine strains. The HI titers against the homologous Re-11 and Re-12 viruses were both 512 (Table 2), whereas the HI titers of the Re-11 antiserum against the four H5N8 viruses were all 16, which is 32-fold lower than that to the homologous titer, and the HI titers of the $\mathrm{Re}-12$ antiserum against the four $\mathrm{H} 5 \mathrm{~N} 8$ viruses were all 
A
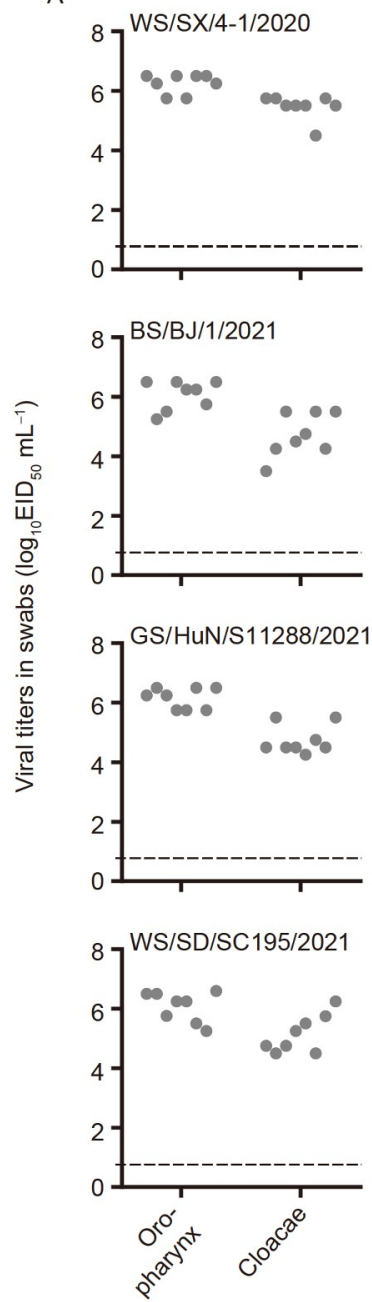

E

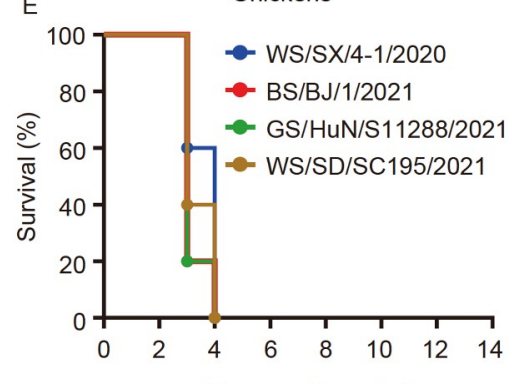

Days post-inoculation


F

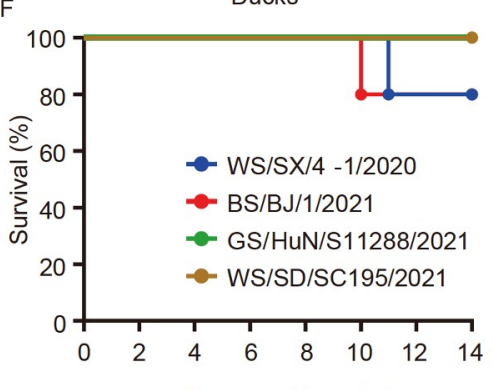

Ducks
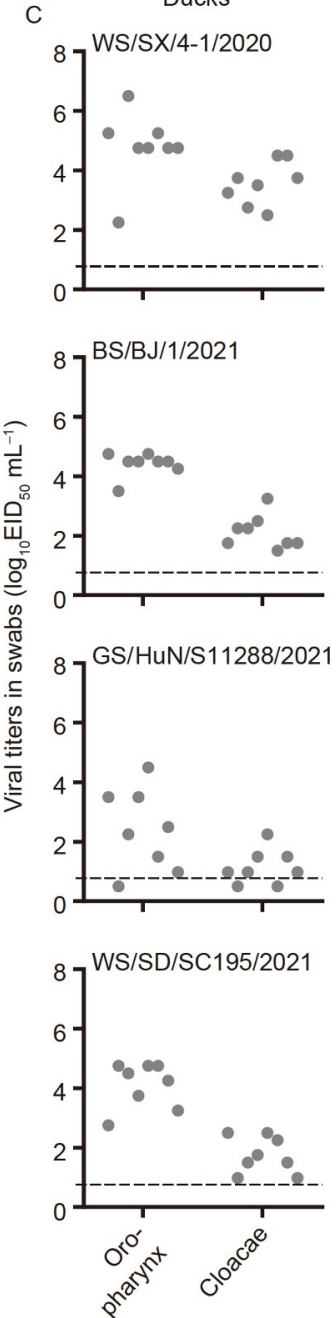
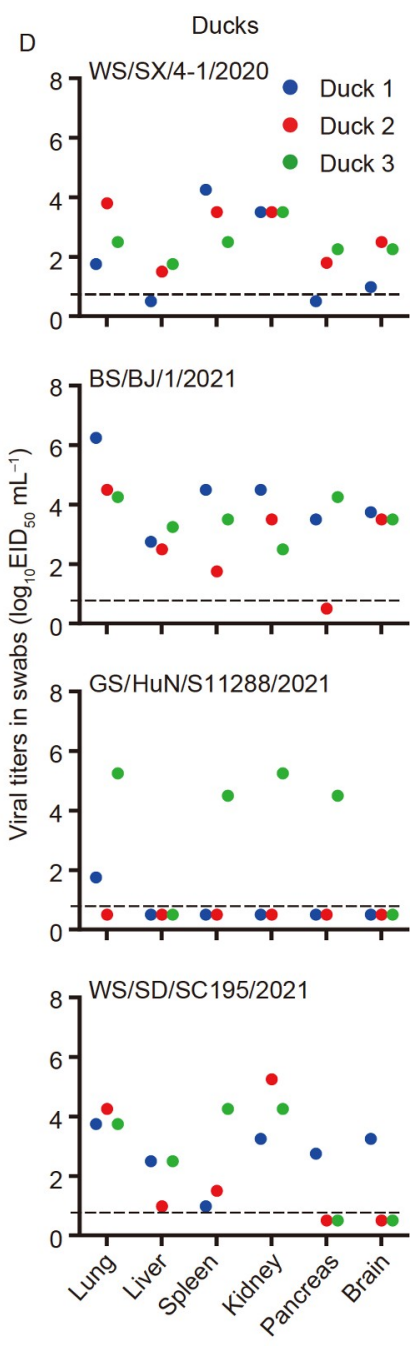

Ducks



Figure 4 Replication and virulence of H5N8 viruses in chickens and ducks. Groups of eight six-week-old specific-pathogen-free chickens or ducks were inoculated i.n. with $10^{6} \mathrm{EID}_{50}$ of the indicated virus in a $0.1-\mathrm{mL}$ volume. Oropharyngeal and cloacal swabs were collected from all birds on Day 3 p.i., and then three birds in each group were euthanized, and their organs were collected for virus titration in eggs. The remaining five birds in each group were observed for death for two weeks. Sera were collected from surviving birds at the end of the observation for antibody detection. A, Viral titers in swabs of chickens. B, Viral titers in organs of chickens. C, Viral titers in swabs of ducks. D, Viral titers in organs of ducks. E, Survival patterns of chickens. F, Survival patterns of ducks. G, Seroconversion of surviving ducks. The red asterisk indicates that one duck in that group died before the serum sample was collected.

8 , which is 64 -fold lower than that to the homologous titer (Table 2). These results indicate that the newly invasive H5N8 viruses differ antigenically from the currently used vaccine.
Protective efficacy of the immunity induced by vaccination in farmed poultry against $\mathrm{H} 5 \mathrm{N8}$ virus challenge

An $\mathrm{H} 5 / \mathrm{H} 7$ trivalent inactivated vaccine developed by using 
Table 2 Cross-reactive HI antibody titers of H5N8 viruses with different antisera

\begin{tabular}{cccc}
\hline & & \multicolumn{2}{c}{$\begin{array}{c}\text { HI antibody titer } \\
\text { of antiserum }\end{array}$} \\
\cline { 3 - 4 } Virus & HA clade & Re-11 & Re-12 \\
\hline Re-11 & $2.3 .4 .4 \mathrm{~h}$ & $\mathbf{5 1 2}$ & 32 \\
Re-12 & $2.3 .2 .1 \mathrm{~d}$ & 16 & $\mathbf{5 1 2}$ \\
WS/SX/4-1/2020(G1) & $2.3 .4 .4 \mathrm{~b}$ & 16 & 8 \\
BS/BJ/1/2021(G1) & $2.3 .4 .4 \mathrm{~b}$ & 16 & 8 \\
GS/HuN/S11288/2021(G1) & $2.3 .4 .4 \mathrm{~b}$ & 16 & 8 \\
WS/SD/SC195/2021(G2) & $2.3 .4 .4 \mathrm{~b}$ & 16 & 8 \\
\hline
\end{tabular}

a) Antisera were generated by vaccinating specific-pathogen-free chickens with the oil-emulsified inactivated viruses indicated in the table; the homologous titers are shown in bold.

the H5N1 Re-11 strain, Re-12 strain, and H7N9 H7-Re3 strain has been used in poultry in China since July 2020 (MARA, 2020). To evaluate how well the vaccine protects poultry against $\mathrm{H} 5 \mathrm{~N} 8$ virus challenge, we purchased 10 chickens and 30 ducks from different local farms. The age and vaccination status of these birds differed: the chickens were 155 days-old and had received three shots of the vaccine, 10 ducks were 88 days-old and had received two shots of the vaccine (two-shot vaccinated ducks), 10 ducks were 52 days-old and had received one shot of the vaccine (oneshot vaccinated ducks), and 10 ducks were 40 days-old and had not been vaccinated (unvaccinated ducks) (Figure 5A). These birds and 10 six-week-old SPF chickens (as controls) were intranasally challenged with the WS/SX/4-1/2020 virus. Blood samples were collected from all birds for antibody detection before challenge.

The HI antibody titers of the sera were measured by using the vaccine seed virus Re-11 and the challenge virus WS/SX/ 4-1/2020. As shown in Figure 5B, the mean HI antibody titer of the layer chickens against Re-11 and WS/SX/4-1/2020 were $9.4 \log _{2}$ and $4.6 \log _{2}$, respectively (Figure 5B); the SPF chickens did not have detectable antibodies against these viruses. Eight of the 10 SPF chickens died before Day 3 postchallenge (p.c.), and the other two shed viruses through both the oropharynx and cloacae on Day 3 p.c. and died on Day 4 p.c., whereas none of the layer chickens from farms shed virus, and all of them survived the $\mathrm{H} 5 \mathrm{~N} 8$ virus challenge (Figure 5C and D).

HI antibody against Re-11 or WS/SX/4-1/2020 was not detected in any of the unvaccinated ducks. The mean antibody titers against the Re-11 virus were $7.7 \log _{2}$ and $8.9 \log _{2}$ in the one-shot vaccinated ducks and two-shot vaccinated ducks, respectively (Figure 5E and F); however, only two of the one-shot vaccinated ducks and seven of the two-shot vaccinated ducks had detectable $\mathrm{HI}$ antibody titers against WS/SX/4-1/2020 (Figure 5E and F). After challenge with $\mathrm{WS} / \mathrm{SX} / 4-1 / 2020$, virus shedding was detected in oropharyngeal and cloacal swabs of all 10 unvaccinated ducks on
Days 3 and 5 p.c., but shedding was not detected in any of the one-shot vaccinated ducks or two-shot vaccinated ducks (Figure 5G). Two ducks in the unvaccinated group died on Day 8 p.c.; whereas all ducks in the one-shot vaccinated and two-shot vaccinated groups survived the H5N8 virus challenge (Figure 5H).

$\mathrm{HI}$ antibody titer has been widely used as an indicator of the immune status of poultry, and a minimal HI antibody titer of $4 \log _{2}$ is thought to be required to secure solid protection. However, the above data show that eight one-shot and two two-shot ducks did not have HI antibodies against WS/SX/4$1 / 2020$ virus (Figure $5 \mathrm{E}$ and $\mathrm{F}$ ), but were still fully protected against the WS/SX/4-1/2020 challenge (Figure 5G and $\mathrm{H}$ ). To understand this unexpected protection of these ducks, we measured the neutralization (NT) antibody in the sera we collected before challenge, and found that 10 and eight oneshot vaccinated ducks had NT antibody titers against Re-11 and WS/SX/4-1/2020, respectively (Figure 5I). Moreover, all 10 two-shot vaccinated ducks had high levels of NT antibodies against both Re-11 and WS/SX/4-1/2020 viruses (Figure 5J), which may partially explain the solid protection observed in these ducks. Two one-shot vaccinated ducks that did not have detectable HI or NT antibody titers to WS/SX/4$1 / 2020$ were also completely protected from the virus challenge, suggesting that other types of immunity induced by vaccination played a role in the protection. Our findings indicate that, although the H5N8 virus has some degree of antigenic difference from the current vaccine strains, poultry routinely vaccinated with the current vaccine could still be completely protected against H5N8 virus challenge.

\section{DISCUSSION}

In this study, we performed extensive surveillance to monitor the invasion and spread of $\mathrm{H} 5 \mathrm{~N} 8$ viruses in China. The H5N8 viruses were first detected from two dead whooper swans found in Shanxi Province in November 2020, and then were detected in ten other different kinds of wild birds and domestic ducks and geese. Genetic analysis of 36 viruses revealed that two distinct genotypes of $\mathrm{H} 5 \mathrm{~N} 8$ viruses were introduced to China by wild birds, and only one of them spread widely to wild birds and domestic waterfowl in China. Animal studies showed that the H5N8 viruses are highly lethal in chickens and cause mild disease in ducks, but their virulence in mice varies among strains. Although there is a clear antigenic difference between the H5N8 viruses and the $\mathrm{H} 5 \mathrm{~N} 1$ vaccine strains currently used in China, vaccinated chickens and ducks in poultry farms could be completely protected against $\mathrm{H} 5 \mathrm{~N} 8$ virus challenge.

H5N8 viruses have been circulating in wild birds since 2014, and are responsible for numerous disease outbreaks in domestic poultry in many countries in Asia, Europe, Africa, 

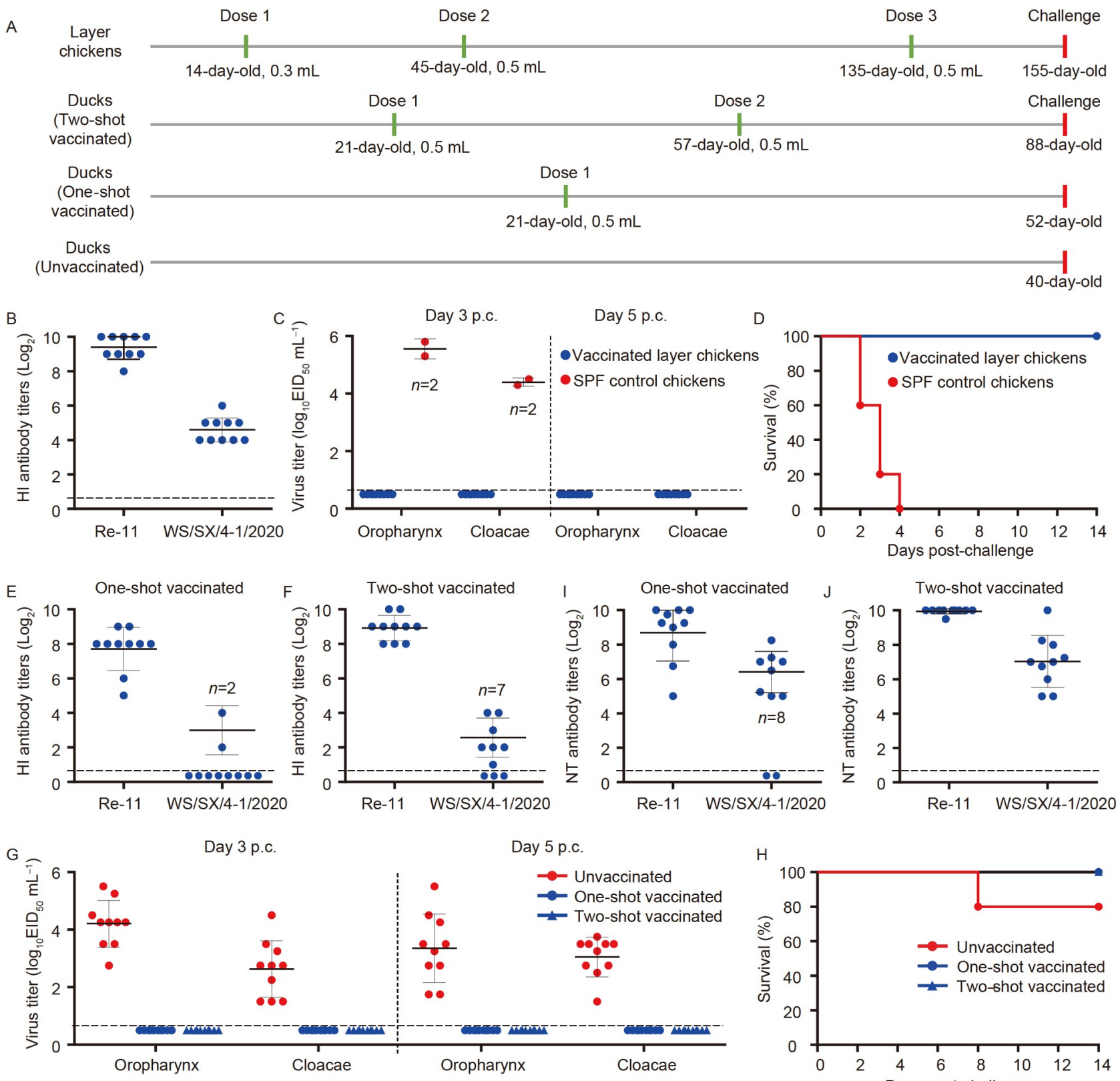

Day 3 p.c.

Day 5 p.c.
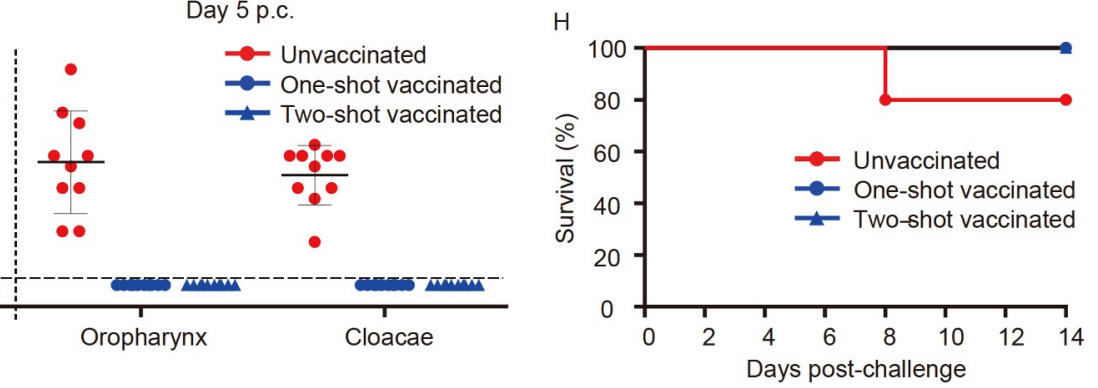

Figure 5 Protection of vaccinated chickens and ducks from H5N8 virus challenge. A, Vaccination status and age information about the farmed chickens and ducks used in this study. B, HI antibody titers of farmed chickens against the indicated viruses. C, Virus shedding of vaccinated layer chickens from poultry farms and SPF control chickens after H5N8 virus WS/SX/4-1/2020 challenge. D, Survival patterns of different chickens after H5N8 virus WS/SX/4-1/2020 challenge. E, HI antibody titers of one-shot vaccinated ducks against the indicated viruses. F, HI antibody titers of two-shot vaccinated ducks against the indicated viruses. G, Virus shedding of different ducks after H5N8 virus WS/SX/4-1/2020 challenge. H, Survival patterns of different ducks after H5N8 virus WS/SX/4-1/2020 challenge. I, NT antibody titers of one-shot vaccinated ducks against the indicated viruses. J, NT antibody titers of two-shot vaccinated ducks against the indicated viruses. The horizontal dashed lines in the panels show the lower limit of virus detection.

and North America (Abolnik et al., 2019; Baek et al., 2021; El-Shesheny et al., 2021; Lee et al., 2015; Napp et al., 2018); however, even though different H5N8 strains have been detected in wild birds and occasionally in ducks or geese in past years, they have not become established in domestic waterfowls and spread or have caused problems in chickens in China. In this study and the studies reported by others (He et al., 2021; Li et al., 2021; Xiong et al., 2021), H5N8 viruses were detected in over 17 different species of wild birds over just a few months. Since it is impossible to prevent wild birds from being infected with the virus, the H5N8 virus may have a high probability of circulation in wild birds in China. We have huge numbers of unvaccinated ducks and geese that are raised in open fields freely contacting wild birds, and it is worrisome that these domestic waterfowls could be easily infected by the H5N8 viruses carried by wild birds. Our 
study showed that the H5N8 viruses are highly lethal in chickens but cause mild infections in ducks, which will enable their spread among ducks without being detected in a timely manner. Although detection of $\mathrm{H} 5 \mathrm{~N} 8$ viruses in ducks and geese in live poultry markets and slaughterhouses indicates that the viruses have been introduced to some ducks and geese in China, it remains to be investigated whether these viruses represent just transient infections or whether they could become established in poultry in China. In either event, extensive surveillance and vaccination should be implemented to prevent possible problems due to the $\mathrm{H} 5 \mathrm{~N} 8$ virus.

Virulence of influenza virus is determined by multiple viral and host factors. The H5N1 viruses bearing the clade 7.2 HA gene are highly lethal to chickens, but cannot replicate in ducks (Li et al., 2010; Liu et al., 2016). The highly pathogenic H7N9 viruses kill chickens quickly but are not fatal to ducks, except for those strains that have acquired some genes from duck viruses (Shi et al., 2018; Yin et al., 2021). The four H5N8 viruses we tested in this study are all highly lethal to chickens, but their virulence in ducks differed: two strains each killed one of the five ducks inoculated, whereas the other two strains did not kill any ducks. The host factors and the underlying mechanisms that limit the replication or virulence of $\mathrm{H} 5$ and $\mathrm{H} 7$ avian influenza viruses in ducks are largely unknown, and identification of these host factors may help in the creation of poultry resistant to avian influenza viruses.

Highly pathogenic avian influenza viruses could be disastrous for domestic poultry if the birds are not vaccinated. The low pathogenic H7N9 virus that emerged in 2013 in China mutated to a highly pathogenic virus in earlier 2017 (Shi et al., 2017), which caused vast avian influenza outbreaks, with millions of chickens being killed in efforts to control the disease (Zeng et al., 2018). Both the low and highly pathogenic H7N9 viruses infected humans (Gao et al., 2013; Yang et al., 2017), with a total of 1,568 infected and 616 deaths (FAO, 2021). However, application of an H7N9 vaccine efficiently prevented the circulation of H7N9 viruses in poultry, and successfully eliminated human infections with H7N9 virus (Zeng et al., 2020). Since October 2020, over 9.8 million domestic poultry in Japan and over 11 million domestic poultry in Korea were killed by the $\mathrm{H} 5 \mathrm{~N} 8$ virus or were destroyed in efforts to contain the outbreaks (http://empres-i.fao.org/eipws3g/). In sharp contrast to Japan and Korea, in China the H5N8 viruses were also detected in wild birds, but they did not cause any disease outbreaks in domestic poultry. Our challenge study showed that routinely vaccinated chickens and ducks in farms were completely protected against a high-dose, lethal H5N8 virus challenge, even among ducks that were only vaccinated with one dose of the vaccine. These findings indicate that poultry vaccination plays a key role in pre- venting $\mathrm{H} 5 \mathrm{~N} 8$ virus from infecting domestic poultry. Given that the $\mathrm{H} 5 \mathrm{~N} 8$ viruses have been detected in a wide range of wild birds over a wide geographic area, it is likely that the viruses will continue to spread worldwide and cause harm to poultry. Therefore, from the perspective of animal welfare, it is strongly recommended that high-risk countries vaccinated their poultry to prevent highly pathogenic $\mathrm{H} 5 \mathrm{~N} 8$ avian influenza.

\section{MATERIALS AND METHODS}

\section{Ethics statements and facility}

The present study was carried out in strict accordance with the recommendations in the Guide for the Care and Use of Laboratory Animals of the Ministry of Science and Technology of China. The protocol was approved by the Committee on the Ethics of Animal Experiments of the Harbin Veterinary Research Institute (HVRI) of the Chinese Academy of Agricultural Sciences. The samples collected through active surveillance were processed in the enhanced biosafety level 2 (BSL2+) facility in the HVRI, and the suspected H5 samples and all the experiments with live H5N8 viruses were carried out in the animal biosafety level 3 (ABSL3) facility in the HVRI.

\section{Sample collection and virus isolation}

Swab samples collected in the live poultry markets, slaughterhouses, and poultry farms, organs or swabs of dead wild birds, and wild bird feces were used for virus isolation. The individual samples were inoculated into 10-day-old embryonated chicken eggs and incubated for $48 \mathrm{~h}$ at $37^{\circ} \mathrm{C}$. The HA subtype was identified by using the HI test and the NA subtype was confirmed by direct sequence analysis. The H5N8 viruses were biologically cloned three times by limiting dilution in embryonated SPF chicken eggs, and the virus stocks were grown in SPF chicken eggs and maintained at $-70^{\circ} \mathrm{C}$.

\section{Genetic and phylogenetic analyses}

Viral RNA (vRNA) was extracted from virus-infected allantoic fluid and cDNA were synthesized from vRNAs by reverse transcription with the Uni12 primer and were amplified by PCR with gene-specific primers. The whole genome of the viruses was sequenced on an Applied Biosystems DNA analyzer (3500xL Genetic Analyzer, Applied Biosystems, USA). The nucleotide sequences were edited with the Seqman module of the DNAStar package. Phylogenetic analysis was performed by using the MEGA 7.0.26 software package, implementing the neighbor-joining method, and was evaluated by 1,000 bootstrap analyses. The HA gene 
was rooted to $\mathrm{A} /$ duck/Anhui/1/2016 (H5N1), and the rest genes of the $\mathrm{H} 5 \mathrm{~N} 8$ viruses were rooted to $\mathrm{A} / \mathrm{breeder}$ duck/ Korea/Gochang1/2014 (H5N8).

\section{Generation of a Bayesian time-resolved phylogenetic tree of the HA gene of $\mathrm{H5N8}$ viruses}

The phylogenetic relationship of the HA gene of H5N8 viruses was inferred with BEAST v1.10.4 by using a molecular clock that placed a timescale on virus evolution to estimate rates of viral evolution and dates of divergence. The HA genes of $242 \mathrm{H} 5 \mathrm{~N} 8$ viruses were used to build the tree. The viruses included the 36 isolates detected in this study, four H5N8 viruses isolated in China by others, and 202 representative viruses that were detected in other countries in 2020 and 2021. The HA sequences generated by other researchers were downloaded from Global Initiative on Sharing All Influenza Data databases (GISAID; https://www.gisaid.org). Phylogeny was estimated within a Bayesian Markov Chain Monte Carlo (MCMC) framework. Evidence of temporal signal for the dataset was evaluated by a linear regression of root-to-tip distance against dates of sampling generated by TempEst v1.5.1 and collection time $\left(R^{2}=0.6205\right.$, correlation coefficient $\left.=0.7877\right)$ for the dataset was demonstrated with valid temporal signal for follow-up studies. The prior model combinations of HA genes were tested by Path Sampling and Stepping Stone Sampling analysis (PS/SSS) (Baele et al., 2012), which employs a mixture of model prior and posterior samples. A range of nucleotide substitution models (GTR $+\mathrm{F}+\mathrm{I}$ (tested by IQtree v1.6.10)) and SRD06 (Shapiro et al., 2006), clock models (strict and relaxed uncorrelated lognormal molecular clock) (Baele et al., 2013), and coalescent tree models (exponential population growth and coalescent Bayesian skyline plot) (Drummond et al., 2005) were specified for model testing by PS/SSS. An MCMC chain for 10,000,000 iterations with sampling every 1,000 steps was run for each model combination and a number of path steps of 50 with the length of each chain being 500,000 iterations were specified for PS/SSS. Model fit was assessed through log marginal likelihoods obtained through PS/SSS. The SRD06 nucleotide substitution model, relaxed uncorrelated lognormal molecular clock and Bayesian Skyline coalescent model were identified with the highest negative log likelihood scores for subsequent analysis. The final MCMC chain was run for 500,000,000 iterations, sampling every 10,000 steps to achieve convergence. The sufficient sampling from the posterior (effective sample size $\geq 200$ ) was assessed by Tracer v1.6.0. A maximum clade credibility (MCC) tree was generated and summarized by TreeAnnotator v1.10.4 discarding $10 \%$ burn-in. The MCC tree was visualized using FigTree v1.4.4. Furthermore, at least two independent runs were performed and compared to ensure adequate sampling.

\section{Replication and virulence of $\mathrm{H5N8}$ viruses in mice}

Six-week-old female BALB/c mice (Beijing Experimental Animal Center, Beijing, China) were lightly anesthetized with $\mathrm{CO}_{2}$ and then inoculated intranasally (i.n.) with $10^{6}$ $\mathrm{EID}_{50}$ of $\mathrm{H} 5 \mathrm{~N} 8$ virus in a volume of $50 \mu \mathrm{L}$. Three mice in each group were euthanized on Day 3 p.i. and their organs, including nasal turbinate, lungs, brain, spleen, and kidneys, were collected for virus titration in chicken eggs. The $M D_{50}$ was determined by inoculating groups of five mice i.n. with 10 -fold serial dilutions containing $10^{1}$ to $10^{6} \mathrm{EID}_{50}$ of the test virus and the mice were observed for weight loss and mortality for 14 days.

\section{Replication and virulence of $\mathrm{H5N8}$ viruses in chickens and ducks}

To determine the replication and virulence of the H5N8 viruses in poultry, groups of eight 6-week-old SPF White Leghorn chickens and SPF ducks (Shaoxing shelduck, a local breed) (National Poultry Laboratory Animal Resource Center, Harbin, China) seronegative for avian influenza viruses were inoculated i.n. with $0.1 \mathrm{~mL}$ of $10^{6} \mathrm{EID}_{50}$ of test viruses. On Day 3 p.i., oropharyngeal and cloacal swabs were collected from all tested birds for virus titration in eggs. Three birds in each group were killed on Day 3 p.i. and their organs (lungs, liver, spleen, kidneys, pancreas, and brain) were collected for virus titration in eggs. The remaining five chickens and ducks were observed for mortality for two weeks; serum from surviving birds was collected for H5 antibody detection.

\section{Antigenic analysis}

Antigenic analysis was performed by using the $\mathrm{HI}$ assay with $1.0 \%$ chicken erythrocytes. Chicken antisera used in this assay were generated in 6-week-old SPF chickens inoculated with $0.5 \mathrm{~mL}$ of oil-emulsified inactivated vaccines that were produced with the currently used $\mathrm{H} 5$ vaccine seed virus Re11 or Re-12, which were described previously (Zeng et al., 2020).

\section{H5N8 virus challenge study in farmed layer chickens and ducks}

Vaccines have been successfully used to control highly pathogenic $\mathrm{H} 5$ and $\mathrm{H} 7$ avian influenza in China (Li et al., 2014; Zeng et al., 2018). To investigate how well poultry in farms is protected against $\mathrm{H} 5 \mathrm{~N} 8$ virus, we purchased 10 commercial layers (Hy-Line Brown) and 30 ducks (Pekin duck) of 
different ages and vaccination backgrounds (see Figure 5A for details) from different local poultry farms in Harbin, Heilongjiang Province of China, and challenged them with $10^{5} \operatorname{EID}_{50}$ (chickens) or $10^{6} \mathrm{EID}_{50}$ (ducks) of the $\mathrm{H} 5 \mathrm{~N} 8$ virus, A/whooper swan/Shanxi/4-1/2020(H5N8) (WS/SX/4-1/ 2020). Ten six-week-old female SPF chickens (White Leghorn) were included as a control group for the challenge study. Serum was collected from all birds before challenge to test their HI antibody titers against the vaccine strain Re-11 and the challenge virus. The neutralization antibody titers of the vaccinated ducks were tested according to the WHO Manual on Animal Influenza Diagnosis and Surveillance (WHO, 2011). On Days 3 and 5 p.c., oropharyngeal and cloacal swabs were collected from all surviving birds and titrated in chicken eggs. All birds were observed for two weeks.

\section{Compliance and ethics The author(s) declare that they have no conflict of interest.}

\begin{abstract}
Acknowledgements This work was supported by the National Natural Science Foundation of China (31521005, 31672593), the Laboratory for Lingnan Modern Agriculture Project (NT2021007), the National Key Research and Development Program of China (2016YFD0500201), and the China Agriculture Research System (CARS-41G12). We thank the authors and submitting laboratories of the sequences from the GISAID EpiFlu Database.
\end{abstract}

Open Access This article is licensed under a Creative Commons Attribution 4.0 International License, which permits use, sharing, adaptation, distribution and reproduction in any medium or format, as long as you give appropriate credit to the original author(s) and the source, provide a link to the Creative Commons licence, and indicate if changes were made. The images or other third party material in this article are included in the article's Creative Commons licence, unless indicated otherwise in a credit line to the material. If material is not included in the article's Creative Commons licence and your intended use is not permitted by statutory regulation or exceeds the permitted use, you will need to obtain permission directly from the copyright holder. To view a copy of this licence, visit http://creativecommons.org/licenses/by/4.0/.

\section{References}

Abolnik, C., Pieterse, R., Peyrot, B.M., Choma, P., Phiri, T.P., Ebersohn, K., Heerden, C.J., Vorster, A.A., Zel, G., Geertsma, P.J., et al. (2019). The incursion and spread of highly pathogenic avian influenza H5N8 clade 2.3.4.4 within south Africa. Avian Dis 63, 149-156.

Ayllon, J., Domingues, P., Rajsbaum, R., Miorin, L., Schmolke, M., Hale, B.G., and García-Sastre, A. (2014). A single amino acid substitution in the novel H7N9 influenza A virus NS1 protein increases CPSF30 binding and virulence. J Virol 88, 12146-12151.

Baek, Y.G., Lee, Y.N., Lee, D.H., Shin, J.I., Lee, J.H., Chung, D.H., Lee, E. K., Heo, G.B., Sagong, M., Kye, S.J., et al. (2021). Multiple reassortants of $\mathrm{H} 5 \mathrm{~N} 8$ clade $2.3 .4 .4 \mathrm{~b}$ highly pathogenic avian influenza viruses detected in South Korea during the winter of 20202021. Viruses 13, 490.

Baele, G., Lemey, P., Bedford, T., Rambaut, A., Suchard, M.A., and Alekseyenko, A.V. (2012). Improving the accuracy of demographic and molecular clock model comparison while accommodating phylogenetic uncertainty. Mol Biol Evol 29, 2157-2167.
Baele, G., Li, W.L.S., Drummond, A.J., Suchard, M.A., and Lemey, P. (2013). Accurate model selection of relaxed molecular clocks in bayesian phylogenetics. Mol Biol Evol 30, 239-243.

Chen, H., Li, Y., Li, Z., Shi, J., Shinya, K., Deng, G., Qi, Q., Tian, G., Fan, S., Zhao, H., et al. (2006). Properties and dissemination of H5N1 viruses isolated during an influenza outbreak in migratory waterfowl in western China. J Virol 80, 5976-5983.

Cui, Y., Li, Y., Li, M., Zhao, L., Wang, D., Tian, J., Bai, X., Ci, Y., Wu, S., Wang, F., et al. (2020). Evolution and extensive reassortment of H5 influenza viruses isolated from wild birds in China over the past decade. Emerg Microbes Infects 9, 1793-1803.

Dalby, A.R., and Iqbal, M. (2015). The European and Japanese outbreaks of H5N8 derive from a single source population providing evidence for the dispersal along the long distance bird migratory flyways. PeerJ 3, e934.

Drummond, A.J., Rambaut, A., Shapiro, B., and Pybus, O.G. (2005). Bayesian coalescent inference of past population dynamics from molecular sequences. Mol Biol Evol 22, 1185-1192.

El-Shesheny, R., Kandeil, A., Mostafa, A., Ali, M.A., and Webby, R.J. (2021). H5 Influenza viruses in Egypt. Cold Spring Harb Perspect Med 11, a038745.

Fan, S., Deng, G., Song, J., Tian, G., Suo, Y., Jiang, Y., Guan, Y., Bu, Z., Kawaoka, Y., and Chen, H. (2009). Two amino acid residues in the matrix protein $\mathrm{M} 1$ contribute to the virulence difference of $\mathrm{H} 5 \mathrm{~N} 1$ avian influenza viruses in mice. Virology 384, 28-32.

FAO. (2021). H7N9 situation update. Available from URL: https://www. fao.org/ag/againfo/programmes/en/empres/H7N9/situation_update. html.

Gao, R., Cao, B., Hu, Y., Feng, Z., Wang, D., Hu, W., Chen, J., Jie, Z., Qiu, $\mathrm{H}$., $\mathrm{Xu}, \mathrm{K}$., et al. (2013). Human infection with a novel avian-origin influenza A (H7N9) virus. N Engl J Med 368, 1888-1897.

Gao, Y., Zhang, Y., Shinya, K., Deng, G., Jiang, Y., Li, Z., Guan, Y., Tian, G., Li, Y., Shi, J., et al. (2009). Identification of amino acids in HA and $\mathrm{PB} 2$ critical for the transmission of $\mathrm{H} 5 \mathrm{~N} 1$ avian influenza viruses in a mammalian host. PLoS Pathog 5, e1000709.

Harfoot, R., and Webby, R.J. (2017). H5 influenza, a global update. J Microbiol 55, 196-203.

Hay, A.J., Zambon, M.C., Wolstenholme, A.J., Skehel, J.J., and Smith, M. H. (1986). Molecular basis of resistance of influenza A viruses to amantadine. J Antimicrob Chemother 18, 19-29.

He, G., Ming, L., Li, X., Song, Y., Tang, L., Ma, M., Cui, J., and Wang, T. (2021). Genetically divergent highly pathogenic avian influenza A (H5N8) viruses in wild birds, eastern China. Emerg Infect Dis 27, 2940-2943.

Hu, M., Yuan, S., Zhang, K., Singh, K., Ma, Q., Zhou, J., Chu, H., and Zheng, B.J. (2017). PB2 substitutions V598T/I increase the virulence of H7N9 influenza A virus in mammals. Virology 501, 92-101.

Jeong, J., Kang, H.M., Lee, E.K., Song, B.M., Kwon, Y.K., Kim, H.R., Choi, K.S., Kim, J.Y., Lee, H.J., Moon, O.K., et al. (2014). Highly pathogenic avian influenza virus (H5N8) in domestic poultry and its relationship with migratory birds in South Korea during 2014. Vet MicroBiol 173, 249-257.

Jiao, P., Tian, G., Li, Y., Deng, G., Jiang, Y., Liu, C., Liu, W., Bu, Z., Kawaoka, Y., and Chen, H. (2008). A single-amino-acid substitution in the NS1 protein changes the pathogenicity of $\mathrm{H} 5 \mathrm{~N} 1$ avian influenza viruses in mice. J Virol 82, 1146-1154.

Khalil, A.M., Fujimoto, Y., Kojima, I., Esaki, M., Ri, K., Masatani, T., Matsui, T., and Ozawa, M. (2021). Genetic characterization of H5N8 highly pathogenic avian influenza viruses isolated from falcated ducks and environmental water in Japan in November 2020. Pathogens 10, 171.

Kim, Y.I., Park, S.J., Kwon, H.I., Kim, E.H., Si, Y.J., Jeong, J.H., Lee, I.W., Nguyen, H.D., Kwon, J.J., Choi, W.S., et al. (2017). Genetic and phylogenetic characterizations of a novel genotype of highly pathogenic avian influenza (HPAI) H5N8 viruses in 2016/2017 in South Korea. Infect Genet Evol 53, 56-67.

Kong, H., Ma, S., Wang, J., Gu, C., Wang, Z., Shi, J., Deng, G., Guan, Y., and Chen, H. (2019). Identification of key amino acids in the PB2 and 
M1 proteins of H7N9 influenza virus that affect its transmission in Guinea pigs. J Virol 94, e01180-19.

Lee, D.H., Torchetti, M.K., Winker, K., Ip, H.S., Song, C.S., and Swayne, D.E. (2015). Intercontinental spread of Asian-origin H5N8 to North America through Beringia by migratory birds. J Virol 89, 6521-6524.

Lewis, N.S., Banyard, A.C., Whittard, E., Karibayev, T., Al Kafagi, T., Chvala, I., Byrne, A., Meruyert (Akberovna), S., King, J., Harder, T., et al. (2021). Emergence and spread of novel H5N8, H5N5 and H5N1 clade 2.3.4.4 highly pathogenic avian influenza in 2020. Emerg Microbes Infects 10, 148-151.

Li, C., Bu, Z., and Chen, H. (2014). Avian influenza vaccines against H5N1 'bird flu'. Trends Biotechnol 32, 147-156.

Li, X., Cui, P., Zeng, X., Jiang, Y., Li, Y., Yang, J., Pan, Y., Gao, X., Zhao, C., Wang, J., et al. (2019). Characterization of avian influenza H5N3 reassortants isolated from migratory waterfowl and domestic ducks in China from 2015 to 2018. Transbound Emerg Dis 66, 2605-2610.

Li, X., Lv, X., Li, Y., Peng, P., Zhou, R., Qin, S., Ma, E., Liu, W., Fu, T., $\mathrm{Ma}, \mathrm{P}$., et al. (2021). Highly pathogenic avian influenza A(H5N8) virus in swans, China, 2020. Emerg Infect Dis 27, 1732-1734.

Li, Y., Shi, J., Zhong, G., Deng, G., Tian, G., Ge, J., Zeng, X., Song, J., Zhao, D., Liu, L., et al. (2010). Continued evolution of H5N1 influenza viruses in wild birds, domestic poultry, and humans in China from 2004 to 2009. J Virol 84, 8389-8397.

Li, Z., Jiang, Y., Jiao, P., Wang, A., Zhao, F., Tian, G., Wang, X., Yu, K., $\mathrm{Bu}, \mathrm{Z}$., and Chen, H. (2006). The NS1 gene contributes to the virulence of H5N1 avian influenza viruses. J Virol 80, 11115-11123.

Liu, J., Xiao, H., Lei, F., Zhu, Q., Qin, K., Zhang, X.W., Zhang, X.L., Zhao, D., Wang, G., Feng, Y., et al. (2005). Highly pathogenic H5N1 influenza virus infection in migratory birds. Science 309, 1206.

Liu, L., Zeng, X., Chen, P., Deng, G., Li, Y., Shi, J., Gu, C., Kong, H., Suzuki, Y., Jiang, Y., et al. (2016). Characterization of clade 7.2 H5 avian influenza viruses that continue to circulate in chickens in China. J Virol 90, 9797-9805.

Ma, S., Zhang, B., Shi, J., Yin, X., Wang, G., Cui, P., Liu, L., Deng, G., Jiang, Y., Li, C., et al. (2020). Amino acid mutations A286V and $\mathrm{T} 437 \mathrm{M}$ in the nucleoprotein attenuate H7N9 viruses in mice. J Virol 94, e01530-19.

MARA. (2020). Bulletin of Ministry of Agriculture and Rural Affairs of China. No. 314. Available from URL: http://www.moa.gov.cn/govpublic/xmsyj/202007/t20200721_6348991.htm.

Napp, S., Majó, N., Sánchez-Gónzalez, R., and Vergara-Alert, J. (2018). Emergence and spread of highly pathogenic avian influenza A(H5N8) in Europe in 2016-2017. Transbound Emerg Dis 65, 1217-1226.

Neumann, G., and Kawaoka, Y. (2006). Host range restriction and pathogenicity in the context of influenza pandemic. Emerg Infect Dis $12,881-886$.

Olsen, B., Munster, V.J., Wallensten, A., Waldenstrom, J., Osterhaus, A.D. M.E., and Fouchier, R.A.M. (2006). Global patterns of influenza a virus in wild birds. Science 312, 384-388.

Pyankova, O.G., Susloparov, I.M., Moiseeva, A.A., Kolosova, N.P., Onkhonova, G.S., Danilenko, A.V., Vakalova, E.V., Shendo, G.L., Nekeshina, N.N., Noskova, L.N., et al. (2021). Isolation of clade 2.3.4.4b $\mathrm{A}(\mathrm{H} 5 \mathrm{~N} 8)$, a highly pathogenic avian influenza virus, from a worker during an outbreak on a poultry farm, Russia, December 2020. Eurosurveillance 26, 2100439.

Rodriguez-Morales, A.J., Bonilla-Aldana, D.K., and Paniz-Mondolfi, A.E. (2021). Concerns about influenza H5N8 outbreaks in humans and birds: facing the next airborne pandemic? Travel Med Infect Dis 41, 102054.

Selim, A.A., Erfan, A.M., Hagag, N., Zanaty, A., Samir, A.H., Samy, M., Abdelhalim, A., Arafa, A.S.A., Soliman, M.A., Shaheen, M., et al. (2017). Highly pathogenic avian influenza virus (H5N8) clade 2.3.4.4 infection in migratory birds, Egypt. Emerg Infect Dis 23, 1048-1051.

Shapiro, B., Rambaut, A., and Drummond, A.J. (2006). Choosing appropriate substitution models for the phylogenetic analysis of protein-coding sequences. Mol Biol Evol 23, 7-9.

Shi, J., Deng, G., Kong, H., Gu, C., Ma, S., Yin, X., Zeng, X., Cui, P., Chen, Y., Yang, H., et al. (2017). H7N9 virulent mutants detected in chickens in China pose an increased threat to humans. Cell Res 27, 1409-1421.

Shi, J., Deng, G., Ma, S., Zeng, X., Yin, X., Li, M., Zhang, B., Cui, P., Chen, Y., Yang, H., et al. (2018). Rapid evolution of H7N9 highly pathogenic viruses that emerged in China in 2017. Cell Host Microbe 24, 558-568.e7.

Shin, D.L., Siebert, U., Lakemeyer, J., Grilo, M., Pawliczka, I., Wu, N.H., Valentin-Weigand, P., Haas, L., and Herrler, G. (2019). Highly pathogenic avian influenza $\mathrm{A}(\mathrm{H} 5 \mathrm{~N} 8)$ virus in gray seals, Baltic Sea. Emerg Infect Dis 25, 2295-2298.

Wang, W., Lu, B., Zhou, H., Suguitan Jr., A.L., Cheng, X., Subbarao, K., Kemble, G., and Jin, H. (2010). Glycosylation at $158 \mathrm{~N}$ of the hemagglutinin protein and receptor binding specificity synergistically affect the antigenicity and immunogenicity of a live attenuated H5N1 A/Vietnam/1203/2004 vaccine virus in ferrets. J Virol 84, 6570-6577.

WHO. (2008). Toward a unified nomenclature system for highly pathogenic avian influenza virus (H5N1). Emerg Infect Dis 14, e1.

WHO. (2011). Manual for the laboratory diagnosis and virological surveillance of influenza. Available from URL: https://apps.who.int/iris/ handle/10665/44518.

Xiong, J., Zhou, H., Fan, L., Zhu, G., Li, Y., Chen, G., Zhang, J., Li, J., Zheng, H., Feng, W., et al. (2021). Emerging highly pathogenic avian influenza (H5N8) virus in migratory birds in Central China, 2020. Emerg Microbes Infects 10, 1503-1506.

Yang, L., Zhu, W., Li, X., Chen, M., Wu, J., Yu, P., Qi, S., Huang, Y., Shi, W., Dong, J., et al. (2017). Genesis and spread of newly emerged highly pathogenic H7N9 avian viruses in mainland China. J Virol 91, e0127717.

Yang, Z.Y., Wei, C.J., Kong, W.P., Wu, L., Xu, L., Smith, D.F., and Nabel, G.J. (2007). Immunization by avian H5 influenza hemagglutinin mutants with altered receptor binding specificity. Science 317, 825-828.

Yin, X., Deng, G., Zeng, X., Cui, P., Hou, Y., Liu, Y., Fang, J., Pan, S., Wang, D., Chen, X., et al. (2021). Genetic and biological properties of H7N9 avian influenza viruses detected after application of the H7N9 poultry vaccine in China. PLoS Pathog 17, e1009561.

Zeng, X., Tian, G., Shi, J., Deng, G., Li, C., and Chen, H. (2018). Vaccination of poultry successfully eliminated human infection with H7N9 virus in China. Sci China Life Sci 61, 1465-1473.

Zeng, X., Chen, X., Ma, S., Wu, J., Bao, H., Pan, S., Liu, Y., Deng, G., Shi, J., Chen, P., et al. (2020). Protective efficacy of an H5/H7 trivalent inactivated vaccine produced from Re-11, Re-12, and H7-Re2 strains against challenge with different $\mathrm{H} 5$ and $\mathrm{H} 7$ viruses in chickens. J Integr Agr 19, 2294-2300.

Zhu, Q., Yang, H., Chen, W., Cao, W., Zhong, G., Jiao, P., Deng, G., Yu, K., Yang, C., Bu, Z., et al. (2008). A naturally occurring deletion in its NS gene contributes to the attenuation of an $\mathrm{H} 5 \mathrm{~N} 1$ swine influenza virus in chickens. J Virol 82, 220-228.

\section{SUPPORTING INFORMATION}

The supporting information is available online at https://doi.org/10.1007/s11427-021-2025-y. The supporting materials are published as submitted, without typesetting or editing. The responsibility for scientific accuracy and content remains entirely with the authors. 